\title{
ESI-MS Studies on the Mechanism of Pd(0)-Catalyzed Three-Component Tandem Double Addition-Cyclization Reaction
}

Hao Guo, ${ }^{a}$ Rong Qian, ${ }^{b}$ Yuanxi Liao, ${ }^{b}$ Shengming Ma,${ }^{a} *$ and Yinlong Guo ${ }^{b}$

${ }^{a}$ State Key Laboratory of Organometallic Chemistry, Shanghai Institute of Organic Chemistry, Chinese Academy of Sciences, 354 Fenglin Road, Shanghai 200032, P. R. China

Fax: (+86)21-64167510, E-mail: masm@mail.sioc.ac.cn

${ }^{b}$ Shanghai Mass Spectrometry Center, Shanghai Institute of Organic Chemistry Chinese Academy of Sciences, 354 Fenglin Road, Shanghai 200032, P. R. China Fax: (+86)21-64166128, E-mail: ylguo@mail.sioc.ac.cn

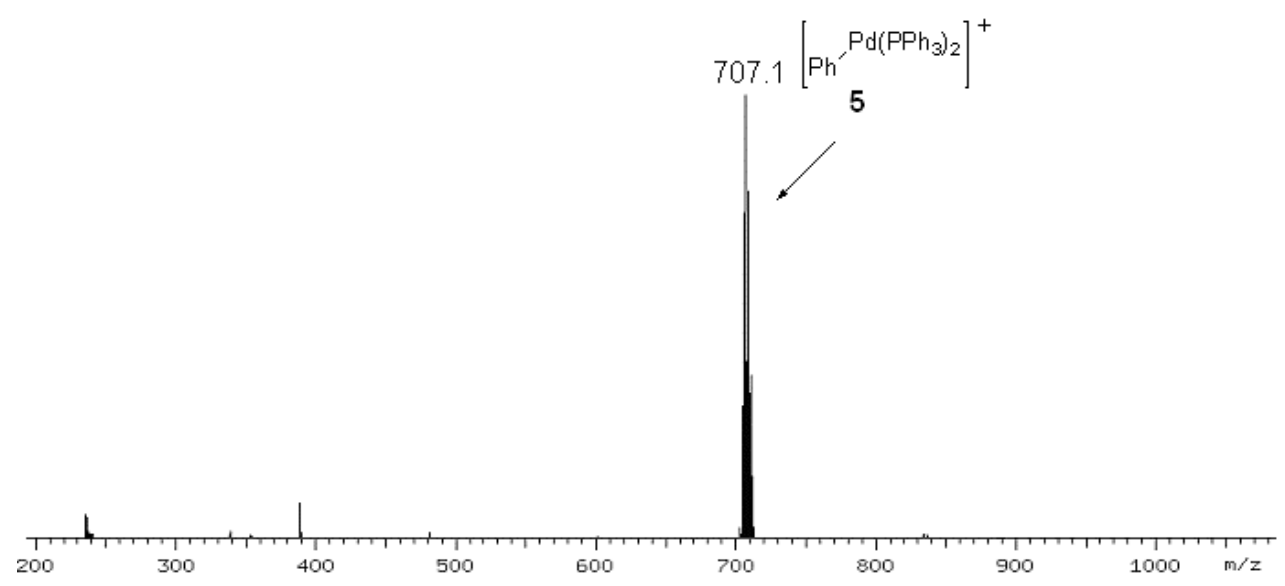

Figure S1. ESI(+)-MS carried out with a CapExit voltage of $52.6 \mathrm{~V}$ for the sample taken from the reaction mixture of iodobenzene $2(0.06 \mathrm{mmol})$ and $\mathrm{Pd}\left(\mathrm{PPh}_{3}\right)_{4}(0.0025$ $\mathrm{mmol})$ in THF $(6 \mathrm{~mL})$ stirred at $\mathrm{rt}$ in a nitrogen atmosphere at the reaction time of 30 min and diluted by the mixed $\mathrm{CH}_{3} \mathrm{CN}$ and $\mathrm{CH}_{3} \mathrm{OH}(\mathrm{v} / \mathrm{v}=1: 1)$. 


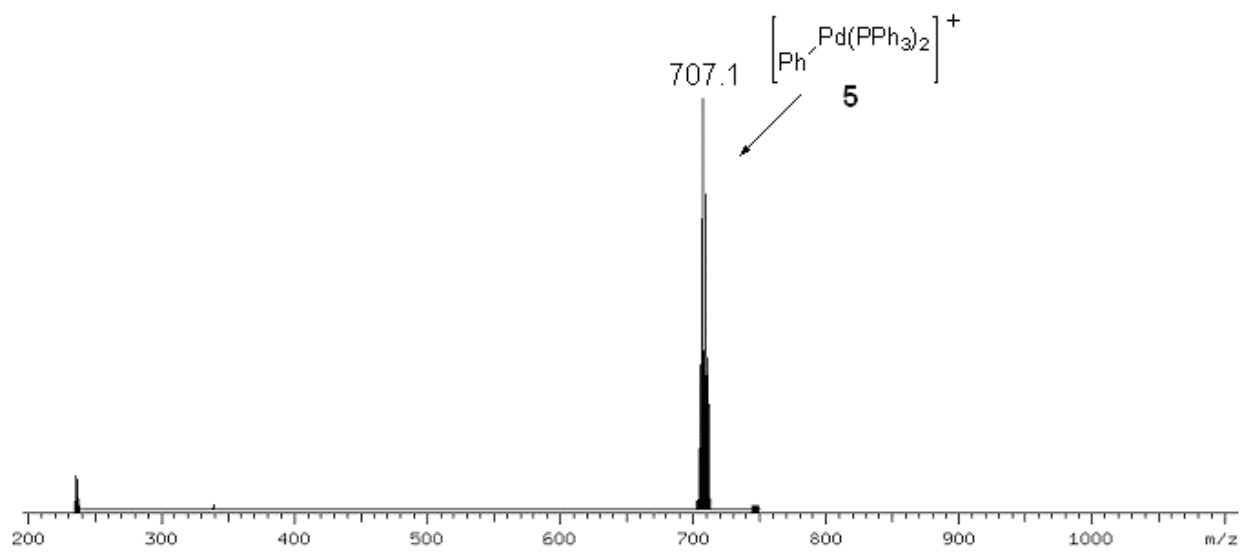

Figure S2. ESI(+)-MS carried out with a CapExit voltage of 52.6 V for the sample taken from the reaction mixture of iodobenzene $2(0.06 \mathrm{mmol})$ and $\mathrm{Pd}\left(\mathrm{PPh}_{3}\right)_{4}(0.0025$ mmol) in THF (6 mL) stirred at $85^{\circ} \mathrm{C}$ in a nitrogen atmosphere at the reaction time of 30 min and diluted by the mixed $\mathrm{CH}_{3} \mathrm{CN}$ and $\mathrm{CH}_{3} \mathrm{OH}(\mathrm{v} / \mathrm{v}=1: 1)$.

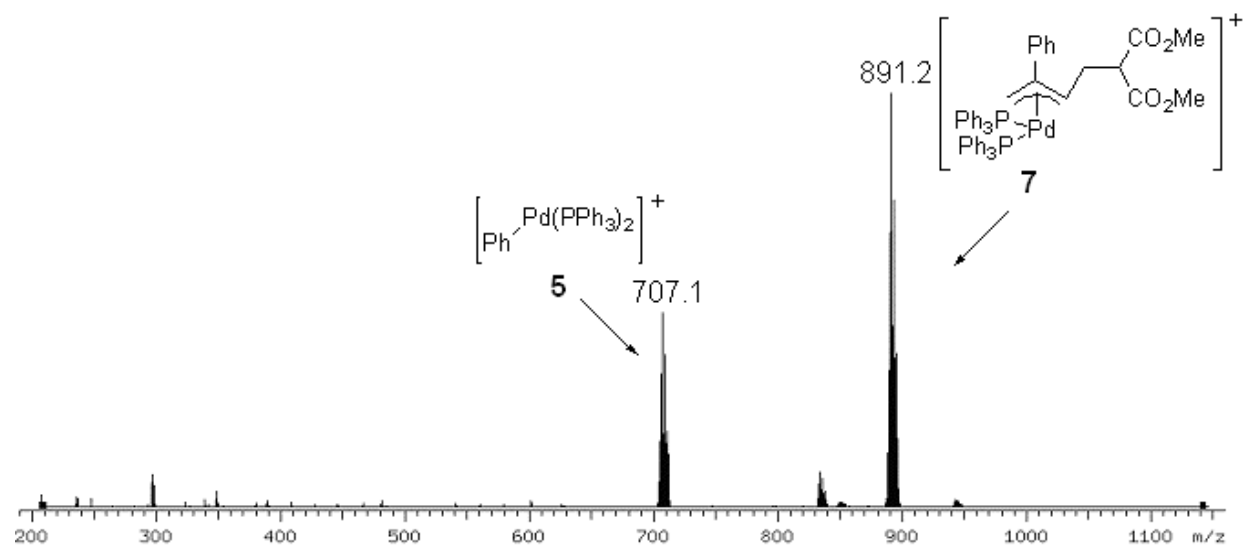

Figure S3. ESI(+)-MS carried out with the standard procedure for MS detection for the sample taken from the reaction mixture of 2-(2, 3-allenyl)malonate $\mathbf{1}$ (0.05 mmol), iodobenzene $2(0.06 \mathrm{mmol})$ and $\mathrm{Pd}\left(\mathrm{PPh}_{3}\right)_{4}(0.0025 \mathrm{mmol})$ in THF $(6 \mathrm{~mL})$ stirred at $85^{\circ} \mathrm{C}$ in a nitrogen atmosphere at the reaction time of $30 \mathrm{~min}$. 


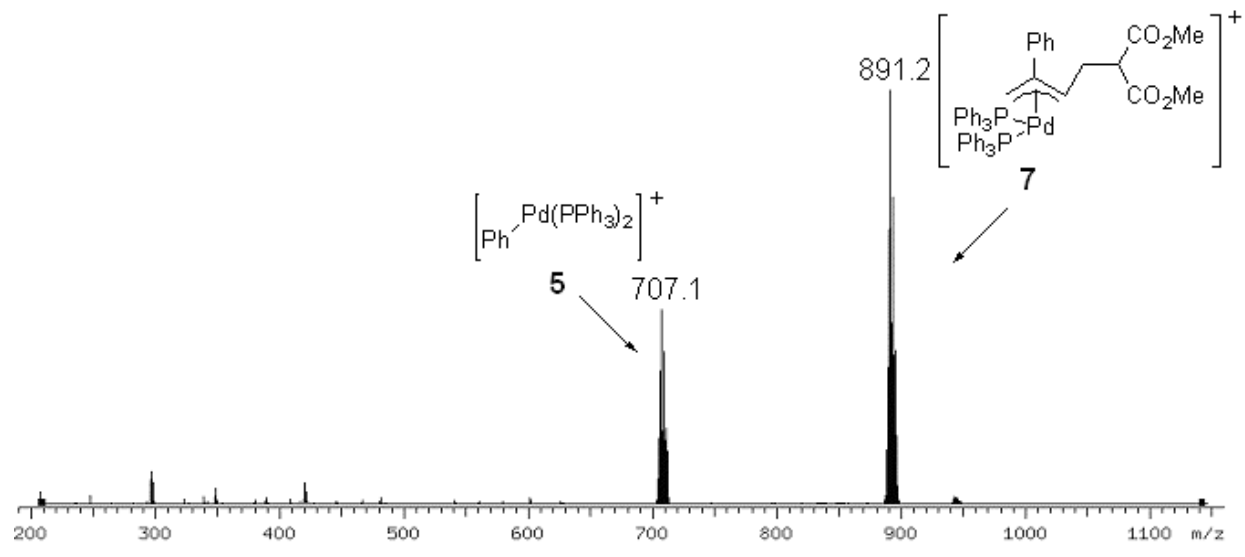

Figure S4. ESI(+)-MS carried out with the standard procedure for MS detection for the sample taken from the reaction mixture of 2-(2, 3-allenyl)malonate $\mathbf{1}$ (0.05 mmol), iodobenzene $2(0.06 \mathrm{mmol})$, imine $3(0.06 \mathrm{mmol})$, and $\mathrm{Pd}\left(\mathrm{PPh}_{3}\right)_{4}(0.0025 \mathrm{mmol})$ in THF (6 mL) stirred at $85^{\circ} \mathrm{C}$ in a nitrogen atmosphere at the reaction time of $1 \mathrm{~h}$. (The MS results for the samples taken at the reaction time between $30 \mathrm{~min}$ to $2 \mathrm{~h}$ were similar to this spectra.) 
a)

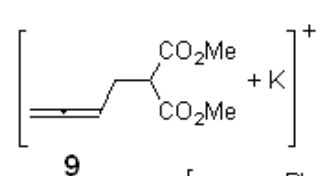

$891.2 \underset{\substack{\mathrm{Ph}_{3} \mathrm{P} \rightarrow \mathrm{Pd} \\ \mathrm{Ph}_{3} \mathrm{P}}}{\mathrm{CO}_{2} \mathrm{Me}}$
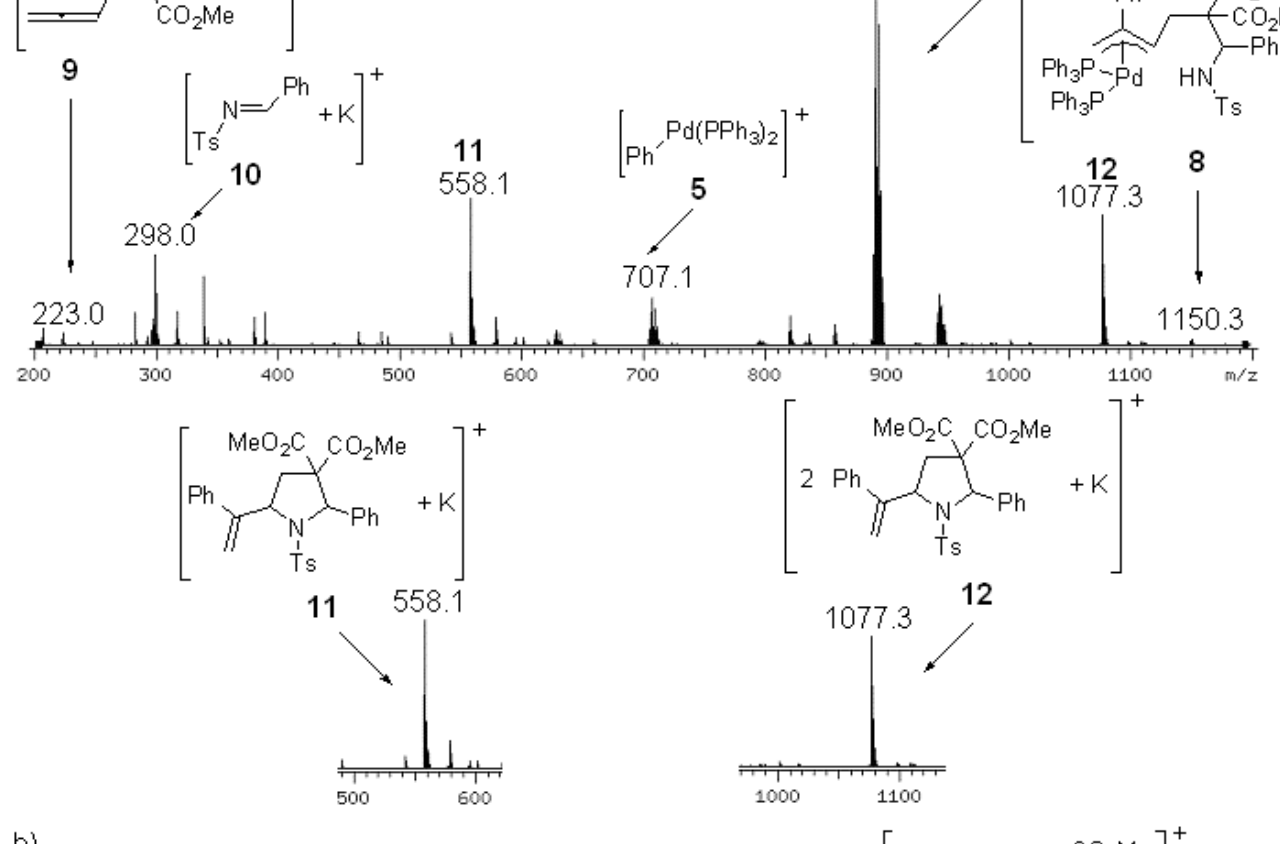

b)
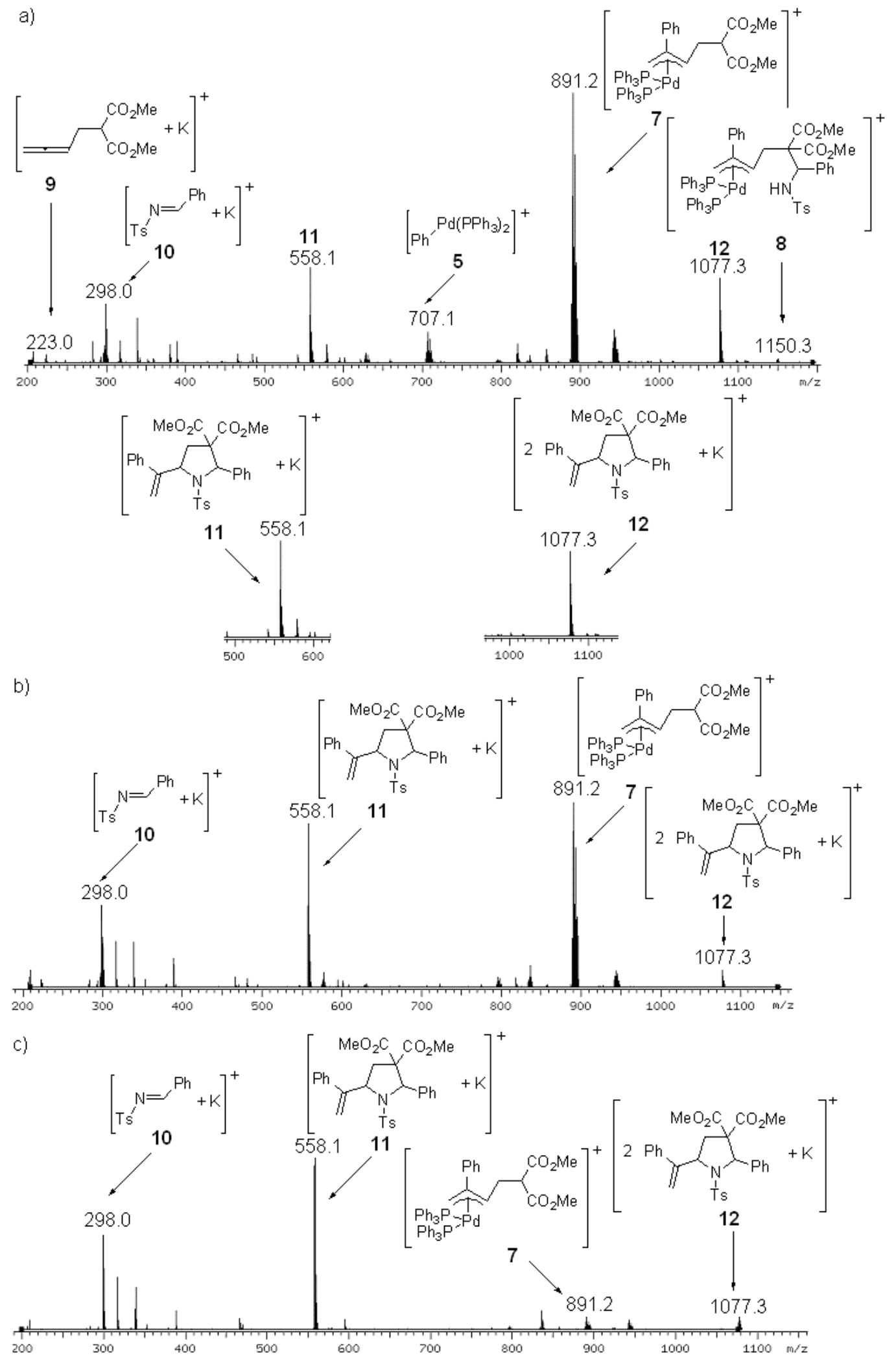


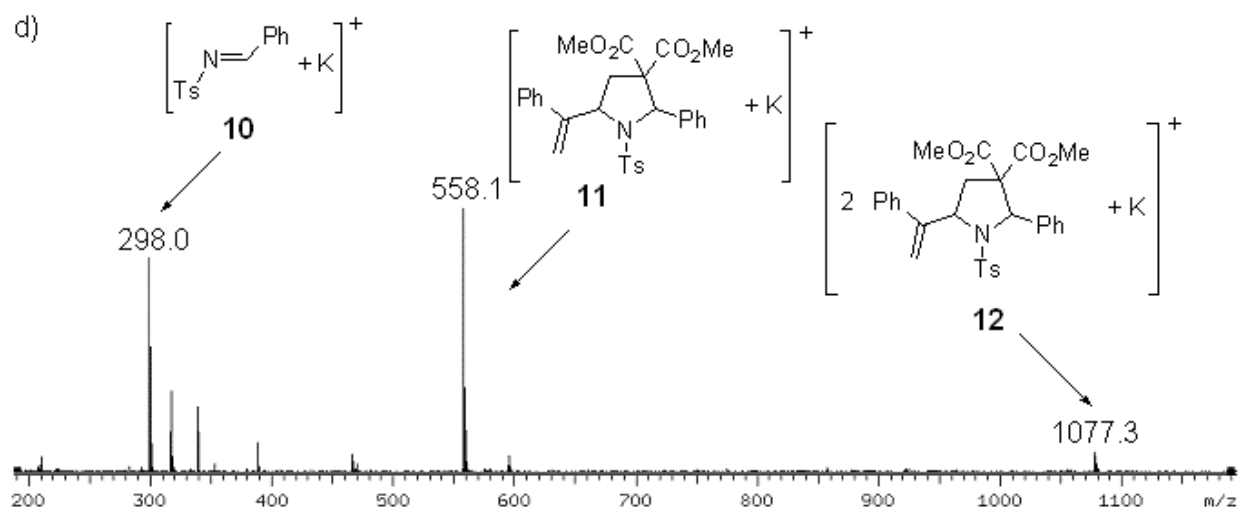

Figure S5. ESI(+)-MS carried out with the standard procedure for MS detection for the sample taken from the reaction mixture of 2-(2, 3-allenyl)malonate $\mathbf{1}(0.05 \mathrm{mmol})$, iodobenzene 2 (0.06 mmol), imine 3 (0.06 mmol), $\mathrm{Pd}\left(\mathrm{PPh}_{3}\right)_{4}(0.0025 \mathrm{mmol})$, and $\mathrm{K}_{2} \mathrm{CO}_{3}(0.05 \mathrm{mmol})$ in THF $(6 \mathrm{~mL})$ stirred at $85^{\circ} \mathrm{C}$ in a nitrogen atmosphere at the reaction time of a) $5 \mathrm{~h}, \mathrm{~b}) 15 \mathrm{~h}, \mathrm{c}) 24 \mathrm{~h}$, and d) $36 \mathrm{~h}$.
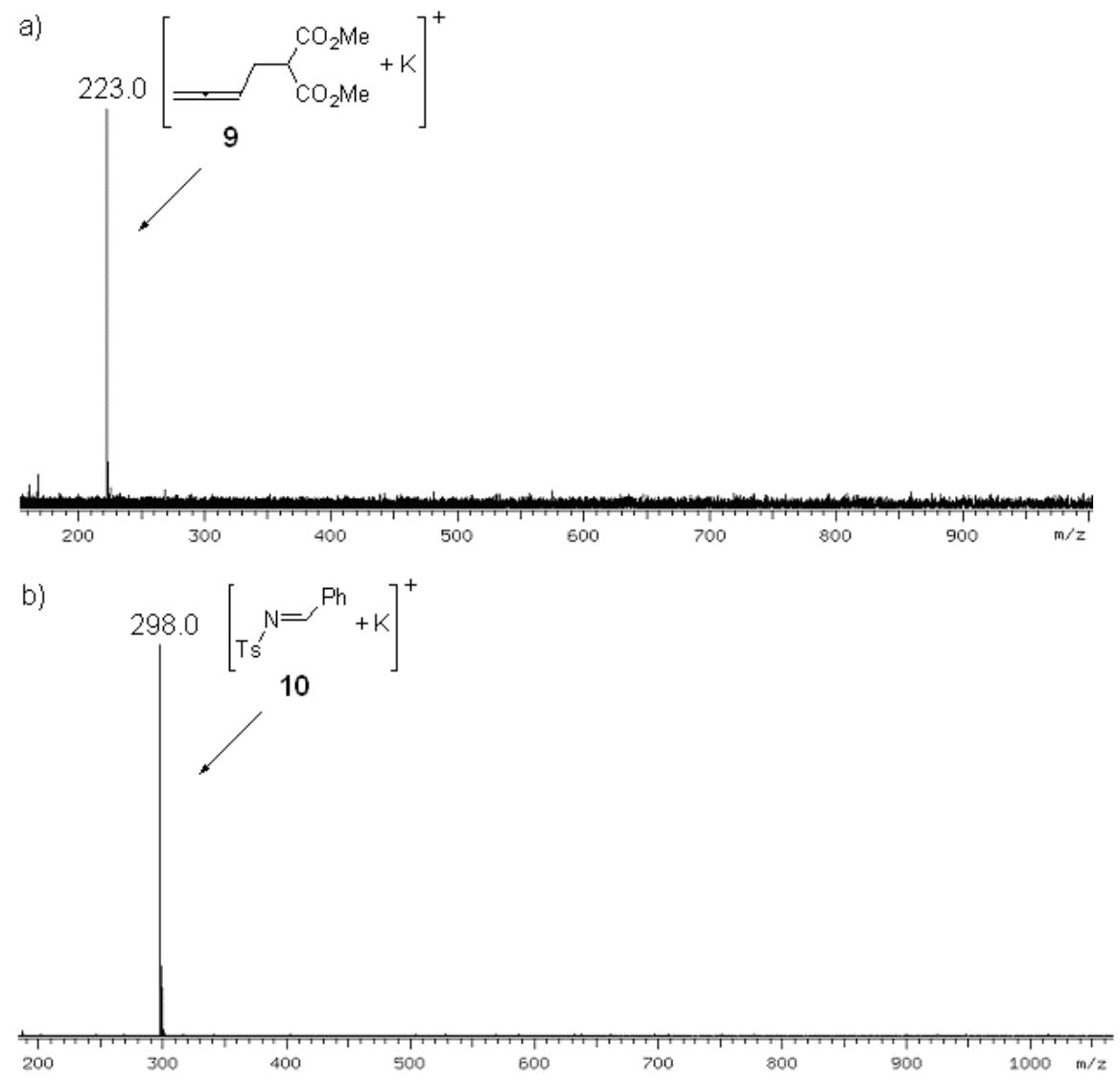

Figure S6. ESI(+)-MS carried out with a CapExit voltage of 52.6 V for a) 2-(2, 
3-allenyl)malonate $\mathbf{1}$ and b) imine 3, diluted by a solution of $\mathrm{CH}_{3} \mathrm{CN}$ saturated with $\mathrm{K}_{2} \mathrm{CO}_{3}$. 


\section{Experimental and theoretical isotopic distribution of the palladium intermediate}

ions.

a) Experimental isotopic distributions of intermediate $\mathbf{5}$.

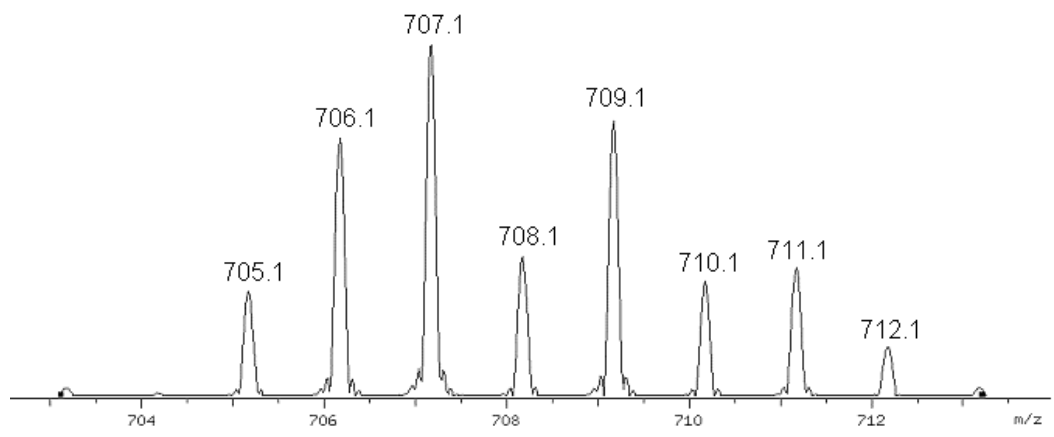

Theoretical isotopic distributions of intermediate $\mathbf{5}$.

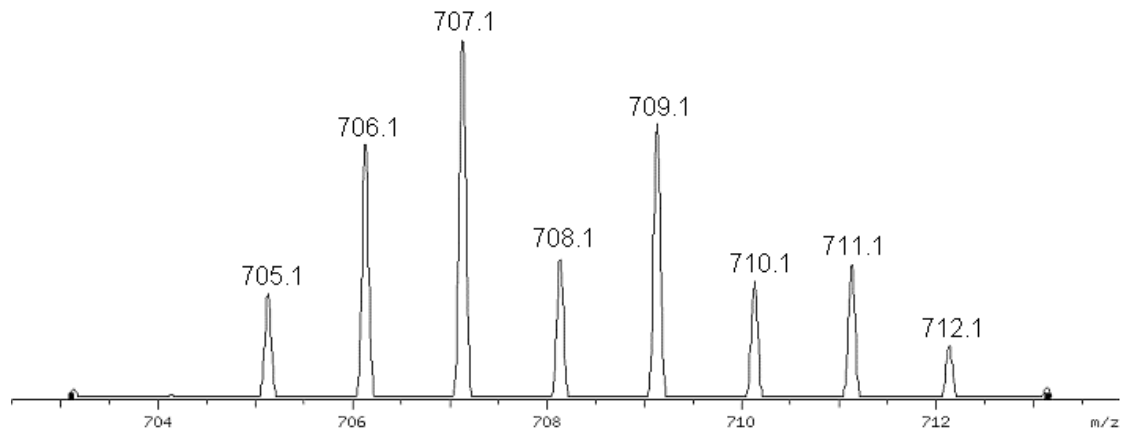

Table 1. Experimental and theoretical isotopic distribution of intermediate 5.

\begin{tabular}{|c|c|c|c|}
\hline$m / z$ & Experimental mass & Theoretical mass & Relative error (ppm) \\
\hline 705.1 & 705.1241 & 705.1249 & -1.1 \\
\hline 706.1 & 706.1264 & 706.1264 & 0 \\
\hline 707.1 & 707.1263 & 707.1259 & 0.6 \\
\hline 708.1 & 708.1292 & 708.1286 & 0.8 \\
\hline 709.1 & 709.1261 & 709.1255 & 0.4 \\
\hline 710.1 & 710.1287 & 710.1284 & 1.0 \\
\hline 711.1 & 711.1278 & 711.1271 & 0.1 \\
\hline 712.1 & 712.1299 & 712.1298 & \\
\hline
\end{tabular}


b) Experimental isotopic distributions of intermediate 6 .

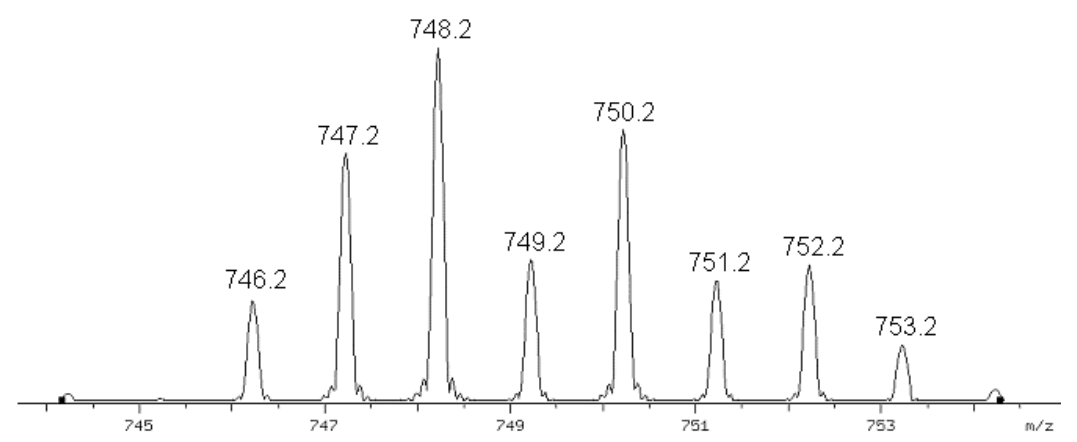

Theoretical isotopic distributions of intermediate 6 .

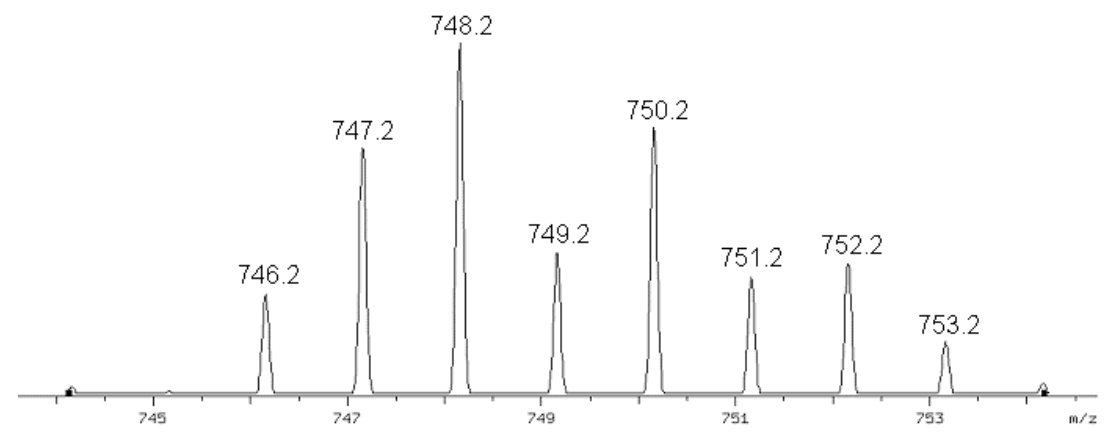

Table 2. Experimental and theoretical isotopic distribution of intermediate 6.

\begin{tabular}{|c|c|c|c|}
\hline$m / z$ & Experimental mass & Theoretical mass & Relative error (ppm) \\
\hline 746.2 & 746.1513 & 746.1515 & -0.3 \\
\hline 747.2 & 747.1529 & 747.1529 & 0 \\
\hline 748.2 & 748.1527 & 748.1525 & 0.3 \\
\hline 749.2 & 749.1550 & 749.1551 & -0.1 \\
\hline 750.2 & 750.1517 & 750.1521 & -0.5 \\
\hline 751.2 & 751.1549 & 751.1549 & 0 \\
\hline 752.2 & 752.1542 & 752.1537 & 0.9 \\
\hline 753.2 & 753.1570 & 753.1563 & \\
\hline
\end{tabular}


c) Experimental isotopic distributions of intermediate 7.

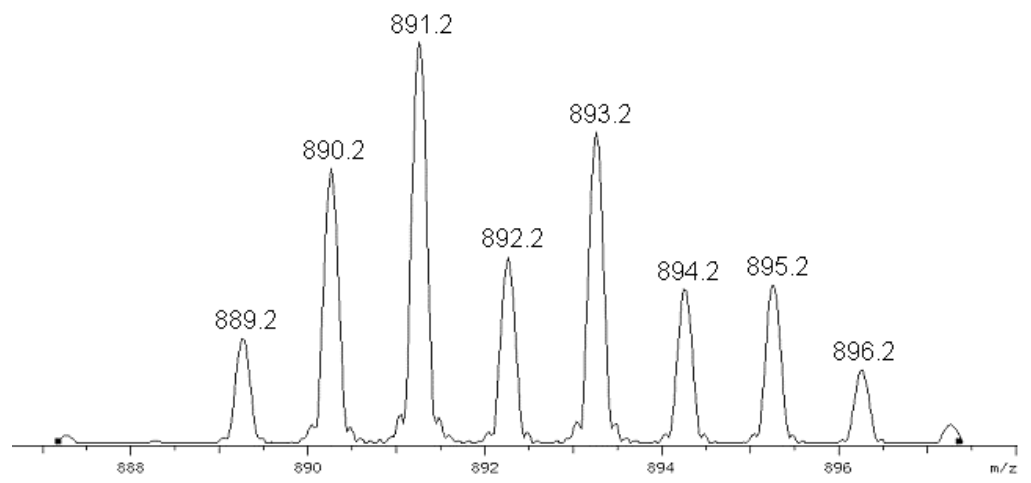

Theoretical isotopic distributions of intermediate 7.

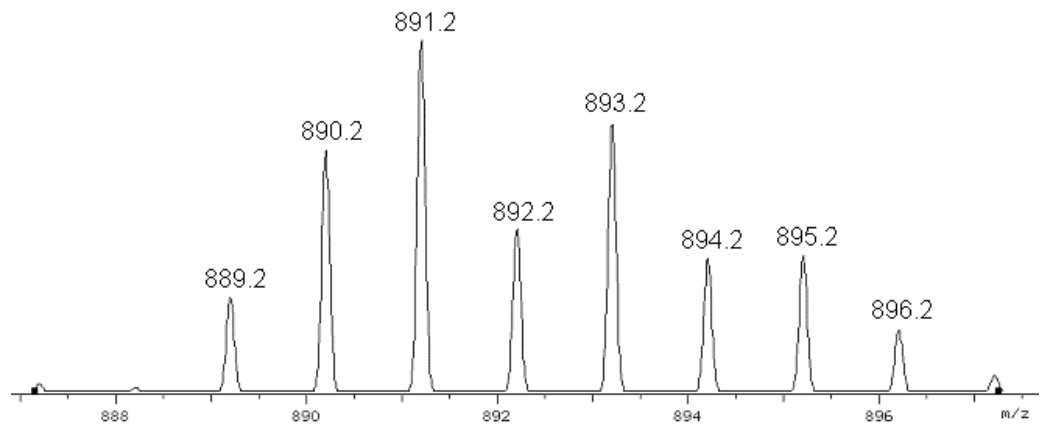

Table 3. Experimental and theoretical isotopic distribution of intermediate 7.

\begin{tabular}{|c|c|c|c|}
\hline$m / z$ & Experimental mass & Theoretical mass & Relative error (ppm) \\
\hline 889.2 & 889.1984 & 889.1986 & -0.2 \\
\hline 890.2 & 890.2006 & 890.2000 & 0.7 \\
\hline 891.2 & 891.1999 & 891.1997 & 0.2 \\
\hline 892.2 & 892.2024 & 892.2023 & 0.1 \\
\hline 893.2 & 893.1992 & 893.1994 & -0.2 \\
\hline 894.2 & 894.2016 & 894.2021 & -0.6 \\
\hline 895.2 & 895.2005 & 895.2011 & -0.7 \\
\hline 896.2 & 896.2029 & 896.2036 & -0.8 \\
\hline
\end{tabular}


d) Experimental isotopic distributions of intermediate $\mathbf{8}$.

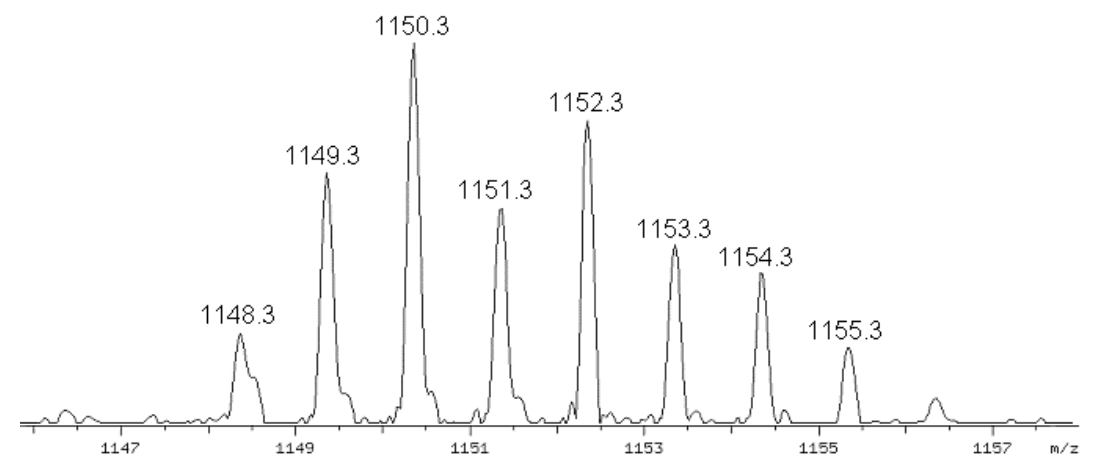

Theoretical isotopic distributions of intermediate $\mathbf{8}$.

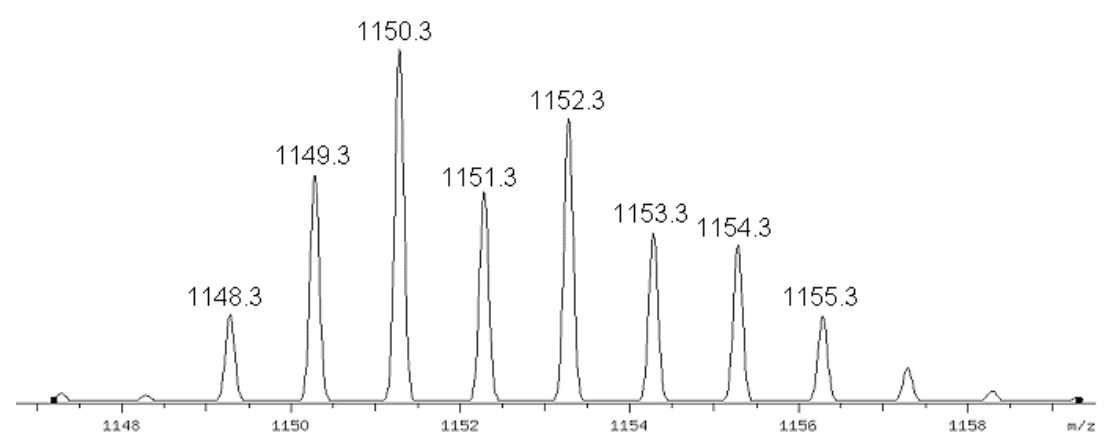

Table 4. Experimental and theoretical isotopic distribution of intermediate $\mathbf{8}$.

\begin{tabular}{|c|c|c|c|}
\hline$m / z$ & Experimental mass & Theoretical mass & Relative error (ppm) \\
\hline 1148.3 & 1148.2659 & 1148.2653 & 0.5 \\
\hline 1149.3 & 1149.2668 & 1149.2667 & 0.1 \\
\hline 1150.3 & 1150.2657 & 1150.2666 & -0.8 \\
\hline 1151.3 & 1151.2680 & 1151.2688 & -0.7 \\
\hline 1152.3 & 1152.2660 & 1152.2665 & -0.4 \\
\hline 1153.3 & 1153.2683 & 1153.2688 & -0.4 \\
\hline 1154.3 & 1154.2684 & 1154.2680 & 0.3 \\
\hline 1155.3 & 1155.2706 & 1155.2701 & 0.4 \\
\hline
\end{tabular}

